\title{
Management of whiplash-associated disorder in the Italian emergency department: the feasibility of an evidence-based continuous professional development course provided by physiotherapists
}

\section{Firas Mourad , Alberto Patuzzo , Andrea Tenci , Gianni Turcato , Agostino} Faletra, Gianluca Valdifiori , Massimiliano Gobbo , Filippo Maselli \& Giuseppe Milano

To cite this article: Firas Mourad , Alberto Patuzzo , Andrea Tenci , Gianni Turcato , Agostino Faletra, Gianluca Valdifiori , Massimiliano Gobbo , Filippo Maselli \& Giuseppe Milano (2020): Management of whiplash-associated disorder in the Italian emergency department: the feasibility of an evidence-based continuous professional development course provided by physiotherapists, Disability and Rehabilitation, DOI: 10.1080/09638288.2020.1806936

To link to this article: https://doi.org/10.1080/09638288.2020.1806936

\section{央 Published online: 27 Aug 2020.}

\section{Submit your article to this journal $\llbracket$}

Q View related articles $\sqsubset$

View Crossmark data $\nearrow$ 


\title{
Management of whiplash-associated disorder in the Italian emergency department: the feasibility of an evidence-based continuous professional development course provided by physiotherapists
}

\author{
Firas Mourad ${ }^{\mathrm{a}}(\mathbb{D})$, Alberto Patuzzo ${ }^{\mathrm{b}}$, Andrea Tenci ${ }^{\mathrm{c}}$, Gianni Turcato ${ }^{\mathrm{d}}$, Agostino Faletra ${ }^{\mathrm{e}}$, Gianluca Valdifiori ${ }^{\mathrm{f}}$, \\ Massimiliano Gobbo $^{\mathrm{g}}$ (D) Filippo Maselli ${ }^{\text {h,i }}$ (D) and Giuseppe Milano

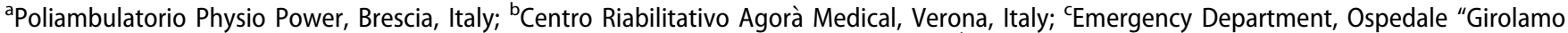 \\ Fracastoro", S. Bonifacio (VR). Aulss 9 "Scaligera" della Regione Veneto, Veneto, Italy; 'Emergency Department, Ospedale Franz Tappeiner

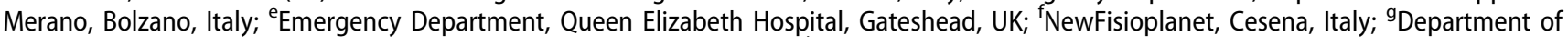

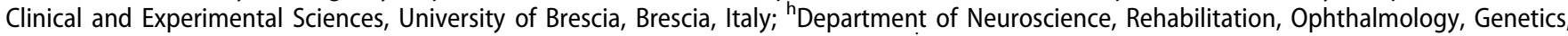 \\ Maternal and Child Health, Campus of Savona, University of Genoa, Savona, Italy; 'Sovrintendenza Sanitaria Regionale Puglia INAIL, Bari, Italy; \\ 'Department of Bone and Joint Surgery, Spedali Civili, Brescia, Italy
}

\section{ABSTRACT}

Purpose: The management of whiplash and associated disorders (WAD) in the Italian Health System is still empirical and influenced by a single professional's expertise. Therefore, the purpose of our study is to describe a structured management changes in an Italian emergency department (ED) after an evidence based continuous professional development (CPD) course.

Methods: A CPD course was organized by Orthopedic Manipulative Physical Therapists (OMPT) for personnel of ED in the hospital Girolamo Fracastoro (San Bonifacio, Verona, Italy), based on latest scientific evidence. Data regarding the number of X-Rays, computed tomography (CT) scan, orthopaedic referrals, neck collars and WAD IV (i.e., severe diagnosis) before and after the course were compared.

Results: 3066 cases of WAD have been analyzed in 2016 and 2185 in 2017/2018. The number of X-Rays dropped down from $15.1 \%$ to $13.5 \%$; the CT scans increased from $1.3 \%$ to $1.9 \%$; the WAD IV diagnosis increased from $0.7 \%$ to $1.6 \%$; the orthopaedic referrals dropped from $1.5 \%$ to $1.1 \%$; the collars prescription dropped from $8.8 \%$ to $2.5 \%$.

Conclusion: An updated framework increased the efficiency of ED's maintaining the same level of safety (i.e., WAD IV diagnosis). Given that, it can also be argued that, in line with other countries, the implementation of an OMPT role within the ED multidisciplinary team is advised also in Italy.

\section{> IMPLICATIONS FOR REHABILITATION}

- Physiotherapists were commissioned to organize a management change of patients in an Italian Emergency Department clinical setting for the management of whiplash;

- Guidelines and other appropriate clinical rules facilitate the delivery of an evidence-based and more appropriate management and care plan;

- An inter-disciplinary continuous professional development course has the potential to positively influence patients' journey and to optimize the use of departmental resources;

- The involvement of other health professionals (e.g., Physiotherapists) within the Italian Emergency Department organizational chart might lead to further improvement of service provided.

\section{ARTICLE HISTORY}

Received 5 March 2020

Revised 3 August 2020

Accepted 4 August 2020

\section{KEYWORDS}

Emergency service; whiplash; patient care team; extended scope physiotherapy; physical therapy specialty

\section{Introduction}

"Whiplash-associated disorder" (WAD) is an umbrella term used to label a variety of symptoms often reported by patients following an acceleration/deceleration injury to the neck that most commonly occurs as a result of a road traffic collision [1]. More than $85 \%$ of these patients experience posterior neck and shoulder pain [2]. Other common symptoms of WADs are cervical spine stiffness, headache, dizziness, numbness, sleeping difficulties, fatigue and cognitive deficits [3]. WAD is often associated with disability, psychological distress and decreased quality of life [1]. These latest non-physical components significantly contribute to either a delayed or incomplete recovery following a whiplash injury. They also lead to doubling the healthcare utilization, its related costs and to considerably longer sick-leave compared to those people presenting with only physical impairments $[1,4,5]$.

Over the past three decades the number of patients attending the Emergency Department (ED) with WAD after road traffic collision has been increasing [6]. The most recent data suggest that more than 300 persons per 100.000 are assessed and treated in EDs every year in Europe and North America [7]. Moreover, in Australia, WAD's comprise $75 \%$ of all survivable road traffic collisions [8]. From an Italian epidemiological perspective, these injuries to the cervical spine represent $45.3 \%$ of all traumas associated to car accidents [9].

The worldwide financial burden of whiplash injuries is huge. That is, in Australia (e.g., Queensland) the costs are substantial 
and exceed $\$ 350$ million per years [10]. In the other Western countries these costs are even more relevant: in the United Kingdom whiplash personal injury claims exceed $£ 3$ billion per year [11], while in the United States the economic costs reach $\$ 242$ billion, including $\$ 23.4$ billion in medical cost and $\$ 77.4$ billion in lost productivity (both market and household) [12]. According to the European Committee of Insurance, the expenditure for these injuries in Italy represents about 33\% of total cost for claimed personal damage [13].

Accurate diagnosis and management of WAD can be challenging for ED clinicians due to a wide variety of possible clinical presentations. The assessment of non-musculoskeletal red flags or serious pathologies, cervical spine fractures or dislocation, disc disruptions and radiculopathies are the mainstay of ED care and usually requires early imaging. However, in the absence of red flags, specific tissue damage or a peripheral lesion cannot be identified as the cause of patient's complaints in most of cases [14]. Given that, "minor trauma" of the neck is the final diagnosis for $85 \%$ of all WAD presenting to EDs [15]. Although the majority of these patients will have a positive prognosis, the importance of early appropriate management is of paramount importance. Inappropriate management within the ED can over-commit resources that could be otherwise be utilized in the treatment of more relevant and pertinent clinical presentations [16]. That is, the X-ray over-usage in the attempt to identify serious pathologies, the administration of pharmacological treatments and the cervical collars prescription have a high impact on the expenses of ED. In addition to this, an excess of human resource, both in term of time and personnel, could be utilized for the management of patients with WADs.

The ED professionals seem to recognize the inappropriate onward referrals to procedures and treatments, such as imaging and pharmacy, as one of the causes of overload of their departments. These criticalities are perceived as a barrier to reach targets, compromise the clinicians' ability to care and put pressure on the department personnel to make clinical decisions without sufficient time [17]. The clinical decision-making process in the ED following these injuries can also influence society productivity cost later on in time in nature of sick-leaves.

Recently, a high number of Evidence based Guidelines [18] have been published with the attempt of improving cost-effectiveness of WAD management and care. First of all, it is recommended to categorize all types of disorders of the cervical region, including WAD, following the Neck Pain Task Force (NPTF) classification [19] to have a better labeling classification, management profile [20] and standardized terminology. WAD can be classified into 4 grades, distinguished by the severity of symptoms, signs and impact on activities of daily life (Table 1).

Clinicians are advised to utilize Canadian Cervical Spine rules (CCR), or other appropriateness criteria, to rule out the need for imaging in acute care setting [21,22]. These rules show very high sensitivity and specificity to detect WAD IV [23,24], and have to be employed in order to reduce unnecessary radiation exposure as well as to drastically reduce costs, without compromising the diagnostic accuracy of serious sequelae (e.g., cervical bony or ligamentous instability) [25].

Another critical aspect is to recognize and consider the prognostic factors (either positive or negative) in order to minimize the risk of residual impairments, with subsequent potential financial implications [25]. Providing advice to stay active and give reassurance is the first-line treatment recommended in most of these guidelines $[18,21,26,27]$. On the other hand, rest and immobilization (including soft collar) are strongly not recommended because of their contribution in developing and reinforcing negative psychological and behavioral attitudes (e.g., kinesiophobia, passive coping, fear-avoidance attitudes, etc.) $[18,21,25,27]$.

In Italy, health professionals who deal with the diagnosis and management of WAD in an ED are nurses during the triage process, the Medical Doctor (MD) engaged for the diagnosis and treatment prescription and subsequently, outside the ED setting, physiotherapists depending on the type and severity of diagnosed WAD. On the basis of our direct experience to the Italian Health System we have noticed that the management of WAD is still empirical and too often influenced by single professional's expertise clinicians often do not offer adequate patient education (e.g., advice to rest). Moreover, unnecessary orthopaedic further assessment and soft collars after discharge are commonly prescribed. This potentially leads to an overloaded system, inappropriate exposure of patients to radiation, increased risk of delayed recovery and significant health, social and insurance costs. Therefore, the aim of our study was to evaluate the impact of a continuous professional development (CPD) course on the management of patients with WAD in an Italian ED setting. The objectives of the course were to adopt a more uniform approach within the ED, based on the best available evidences on: the appropriate use of radiological imaging, the ability of detecting highest severity of the pathology, the correct onward referral to specialty for further assessment and the use of evidence-based management after the discharge (e.g., Schanz collar prescription). Furthermore, the potential advantages of the presence of the Orthopaedic Manipulative Physical Therapist (OMPT) professionals in ED is also discussed. The International Federation of Orthopaedic Manipulative Physical Therapists-a subgroup of the World Confederation for Physical Therapy-defined the Orthopaedic Manipulative Physical Therapy as a specialized area of physical therapy for the management of neuro-musculoskeletal conditions, based on clinical reasoning, using highly specific treatment approaches including manual therapy and therapeutic exercises. Orthopaedic Manipulative Physical Therapy also encompass, and is driven by, the available scientific and clinical evidence and the biopsychosocial framework of each individual person.

\section{Materials and methods}

The project was born as the result of a professional confrontation between ED physicians and Orthopedic Manipulative Physiotherapists (OMPT) on the management of patients with WAD in San Bonifacio ED (Ospedale Girolamo Fracastoro, via Circonvallazione, 1, 37047 San Bonifacio VR). That is, the clinical management of these patients was

Table 1. Classification of neck pain-associated disorders (NAD) and whiplash-associated disorders (WAD).

The 2000-2010 bone and joint decade task force on neck pain and its associated disorders classification of NAD

Grade Definition

No signs or symptoms suggestive of major structural pathology and no or minor interference with activities of daily living

II No signs or symptoms of major structural pathology, but major interference with activities of daily living

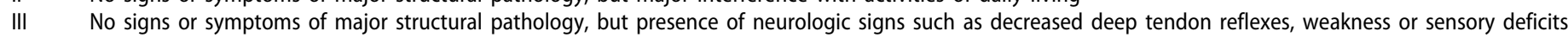
IV Signs or symptoms of major structural pathology 
Table 2. Pre and post- course comparison of the WAD management strategies in the ED.

\begin{tabular}{|c|c|c|}
\hline & PRE-COURSE USUAL CARE & UPDATED POST-COURSE CARE PATHWAY \\
\hline \multirow[t]{5}{*}{ Screening and Evaluation } & $\begin{array}{l}\text { Screening and evaluation based on Orthopaedic } \\
\text { physician's discretion }\end{array}$ & Care pathway framework adoption, including human resources rules \\
\hline & Non standardized patient's classification & 4 grades neck-pain task force WAD classification \\
\hline & $\begin{array}{l}\text { Imaging use based on Orthopeadic } \\
\text { physician evaluation }\end{array}$ & $\begin{array}{l}\text { The use of Canadian Cervical Spine rules for the vertebral fracture/ } \\
\text { dislocation ruling out process; Imaging prescriptions based on the } \\
\text { use of Canadian Cervical Spine rules and imaging diagnostic } \\
\text { accuracy and cost-effectiveness (CT scan VS X-ray) }\end{array}$ \\
\hline & WAD IV evaluation based on the clinician's expertise & $\begin{array}{l}\text { The use of Canadian Cervical Spine rules for the vertebral fracture/ } \\
\text { dislocation ruling out process; Imaging prescriptions based on the } \\
\text { use of Canadian Cervical Spine rules and their diagnostic accuracy } \\
\text { (CT scan VS X-ray). } \\
\text { Update on risk factors and clinical signs and symptoms for the } \\
\text { screening of other medical conditions (e.g., cervical vascular } \\
\text { pathologies) }\end{array}$ \\
\hline & WAD III evaluation based on the clinician's expertise & $\begin{array}{l}\text { Update on risk factors, clinical signs and symptoms, clinical } \\
\text { evaluation, and testing for the screening of other medical } \\
\text { conditions (e.g., peripheral neuropathic pain) }\end{array}$ \\
\hline \multirow[t]{5}{*}{ Management } & $\begin{array}{l}\text { Management based on Orthopaedic } \\
\text { physician's discretion }\end{array}$ & Care pathway framework adoption, including human resources rules \\
\hline & $\begin{array}{l}\text { Cervical immobilization with soft/rigid collar based } \\
\text { on clinician's judgment }\end{array}$ & $\begin{array}{l}\text { Avoidance of the use of the soft collar stimulating patient active } \\
\text { mobilization; the collar's use is allowed intermittently in case gives } \\
\text { symptoms reduction or because the patient's preferences/beliefs } \\
\text { (including payment policies) }\end{array}$ \\
\hline & $\begin{array}{l}\text { Routine Orthopedic physician referral for } \\
\text { management prescription }\end{array}$ & $\begin{array}{l}\text { Orthopaedic physician referral based on symptoms severity based on } \\
\text { the } 4 \text { grades classification (WAD IV-III); encourage direct physical } \\
\text { therapy referral for a multi-modal care management for WAD with } \\
\text { positive prognosis (WAD I-II) }\end{array}$ \\
\hline & $\begin{array}{l}\text { Resting and passive modalities/therapies (e.g., only } \\
\text { medications) recommendation }\end{array}$ & $\begin{array}{l}\text { Encourage active lifestyle, active coping in order to reduce the } \\
\text { negative prognostic factors and avoid symptoms' persistence }\end{array}$ \\
\hline & $\begin{array}{l}\text { Protect the neck from potential further damages } \\
\text { and movement avoidance to avoid } \\
\text { symptoms worsening }\end{array}$ & $\begin{array}{l}\text { Provide education about pain neurophysiology and benefit of stay } \\
\text { active, combined with early OMPT physical therapy referral for a } \\
\text { multimodal-care management (i.e., supervised exercise, self-efficacy } \\
\text { strategies, education, manual therapy) }\end{array}$ \\
\hline
\end{tabular}

The course was based on the best available evidences and consisted of both theoretical and practical aspects covering the following main contents.

heterogeneous and based only on professionals' personal choice, knowledge and background. The lack of a standard management pathway, in parallel with the need of allocation of resources, suggests the need to design a more standardized updated framework. Two OMPTs with experience in education (FM and AP) were commissioned by direct call to structure a course based on clinical practice guidelines and the best available evidence and the main needs of the ED. Then, a multi-disciplinary team composed by OMPTs, ED physicians and ED nurses, reviewed the course's content in order to increase the generalizability for the specific setting. The 2 physiotherapists delivered the in-house CPD course focused on WAD assessment and management in February and March 2017. The course consisted of both theoretical and practical aspects covering the relevant topics for the setting such as epidemiology, economics cost and EBM management of WAD I-IV: the main content with a comparison of the pre and post-course strategies are summarized in Table 2. An updated care pathway framework with ED's human resources positions was also presented (Figure 1). It took a total of $4 \mathrm{~h}$ to be completed and it was held 3 times to allow all ED's staff to participate (14 ED physicians and 26 ED nurses).

The physical therapists also developed a Patient Information Leaflet that ED's physicians handed out to WAD patients during the consultations. The Patient Information Leaflet was designed on the updated recommendations (Table 2) to be used as an educational tool during the visits in ED and provided understandable information about the nature and recovery of WAD, the use of imaging, the use of the collar, the implications of staying active, on what it is and why is important an early OMPT physical therapy management, and advices to encourage the patient's self-efficacy by staying active and few simple exercises (Figure 2).
After that, we conducted a retrospective analysis of WAD patients admitted to the ED in two different timeframes: from 1 January 2016 to 31 December 2016 (year 2016) and after the completion of the CPD course (from 1 April 2017 to 31 March 2018 -year 2017/2018).

Patients were included in the study if their diagnosis at the ED access was recorded as one of the following keywords: "Neck Pain," "Whiplash," "Cervical Strain," "Neck Strain," "Neck Strain Sprain," "Cervical Strain," "Neck Sprain." The team gathered data regarding the number of X-rays and computed tomography (CT) scan requested, the number of cervical fracture (WAD IV) diagnosed, the number of referrals to Orthopaedic consultations and the number of Schanz collars provided as part of the treatment. The collection of data was done in an anonymous manner. Data were presented as absolute and relative percentages. The statistical analyses were conducted to compare the data belonging to year 2016 with respect to year 2017-2018 by using chi-squared tests (Sigmaplot 11.0; Systat Software Inc.).

\section{Results}

In 2016, ED's hospital registered 55.134 admissions, of which $3.066(5.6 \%)$ had a WAD. Four hundred and sixty-two (15.1\%) XRays and thirty-nine (1.3\%) CT scans was prescribed, for a total of $16.4 \%$ patients who received imaging. Twenty-two patients $(0.7 \%)$ had a cervical fracture (WAD IV), forty-five (1.5\%) underwent an orthopaedic specialty assessments and Schanz collar was prescribed to two hundred and seventy-one (8.8\%) patients on discharge. 


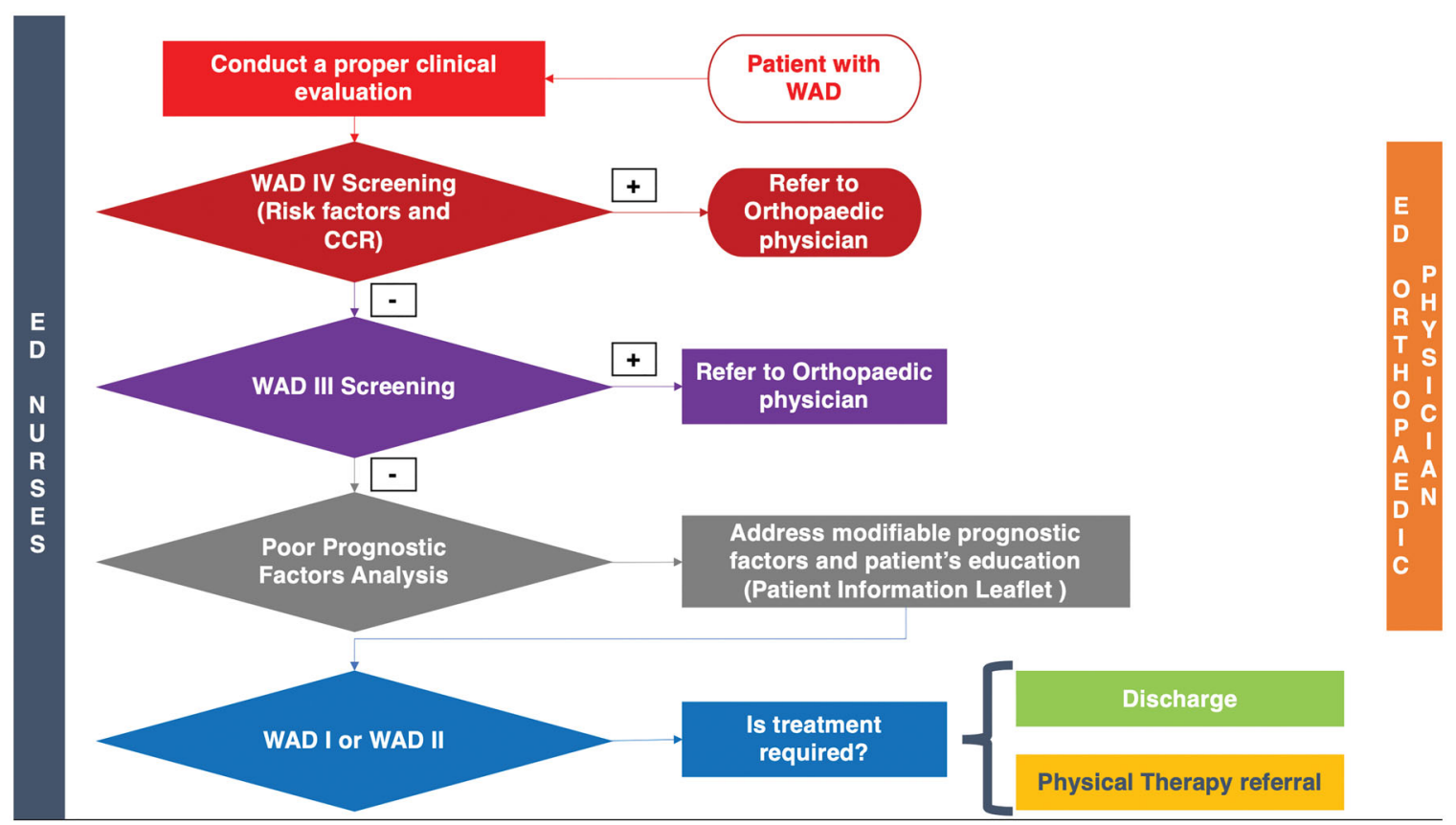

Figure 1. The updated care pathway framework with ED's human resources positions.

In the period analyzed after the CPD course (year 2017/2018), a total of 54.785 patients presented to ED, including 2.185 (3.9\%) with WAD. The $15.4 \%$ of patients received imaging, consisting of 297 (13.5\%) X-rays and 41 (1.9\%) CT scans. Thirty-four (1.6\%) patients had a cervical fracture (WAD IV), twenty-four (1.1\%) have undergone an orthopaedic specialty assessments and fifty-five (2.5\%) received Schanz collar prescription on discharge.

The summary of the results is showed in Table 3.

The increase in WAD IV diagnoses and the reduction of collar prescription in 2017-2018 compared to 2016 were statistically significant ( $p<0.05$ and $p<0.01$, respectively). No significant differences were found for the other variables (number of X-ray exams, number of CT scans, number of orthopaedic referrals).

\section{Discussion}

This study highlights the impact of a CPD course based on the best available evidence for the management of patients with WAD in ED. We observed that the total number of WAD diagnoses in 2017/2018 compared to 2016 decreased significantly from $5.6 \%$ to $3.9 \%(p=0.001)$. It can be assumed that using a standardized classification and definition (Table 1) [19] may helped in appropriately and homogeneously labelling patients between the ED's staff.

The CCR has been shown to be a valid and reliable clinical tool improving the health care resources efficiency [28]. That is, Coffey et al. [23] reported a cervical spine radiographs reduction of $17.4 \%$ using the CCR without compromising patient safety. Additionally, it has been shown that reducing the number of X-rays leads to a reduction of costs, waiting times and unnecessary radiation exposure for patients $[25,29,30]$. Although statistically not significant, our data showed that the adoption of CCR led to a more appropriate imaging requests with a reduction of X-rays performed in the last year analyzed compared to 2016. Furthermore, we observed a tendency to increase CT scans use in the period 2017/2018. In the authors opinion what we observed reflect an early change in usual practice of ED's staff due to the use of the CCR in their clinical decision-making process regarding imaging and may indicate a deeper understanding about the accuracy values of imaging procedures in appropriately diagnose cervical fractures. That is, the application of CCR in emergency setting has been previously shown to increase the appropriateness in CT scan prescription [31]. Holmes and Akkinepalli [32] found that the pooled sensitivity for identifying patients with cervical spine injury was $52 \%$ for plain radiography versus $98 \%$ for CT. This findings are in line with Ngatchou et al. [33] who reported good quality cervical X-rays in only $37.7 \%$ of ED's patients following a cervical blunt trauma. Interestingly, Gale et al. [34] concluded that plain cervical spine radiographs are inadequate to fully evaluate the cervical spine after blunt trauma, and supplemental CT is commonly required. Several others studies have suggested the superiority of CT in moderate to high-risk adults $[32,35]$ as well as in lower risk context $[36,37]$. On the other hand, the systematic use of CT for the initial evaluation of blunt cervical spine injury raises the problem of radiation exposure [38,39] and higher costs [40]. Despite that, two studies showed that CT scan is more cost-effective, especially in moderate-risk to high-risk of cervical fractures $[35,41]$.

Although the total number of WAD diagnosis significantly decreased, the cervical fracture detection increased significantly from $0.7 \%$ to $1.6 \%(p=0.006)$. We assume that the CPD course guaranteed a more appropriate approach to detect cervical spinal fracture or dislocation by the CCR adoption as screening tool that may helped in better selecting which patients were in need of a more appropriate CT scan instead of a less accurate X-ray imaging. Indeed, the CCR have consistently high sensitivity, indicating that a negative test result is highly informative in excluding a clinically important cervical spine injury [42]. Our results could also indicate a lower rate of possible misdiagnosis of serious pathologies. It has not been possible to analyze re-attendances to ED so a comparison about the reliability of the screening process for WAD IV among the years analyzed has not been possible. Nonetheless, a large-scale study reported no missed fracture or adverse outcome when CCR are applied [43]. 

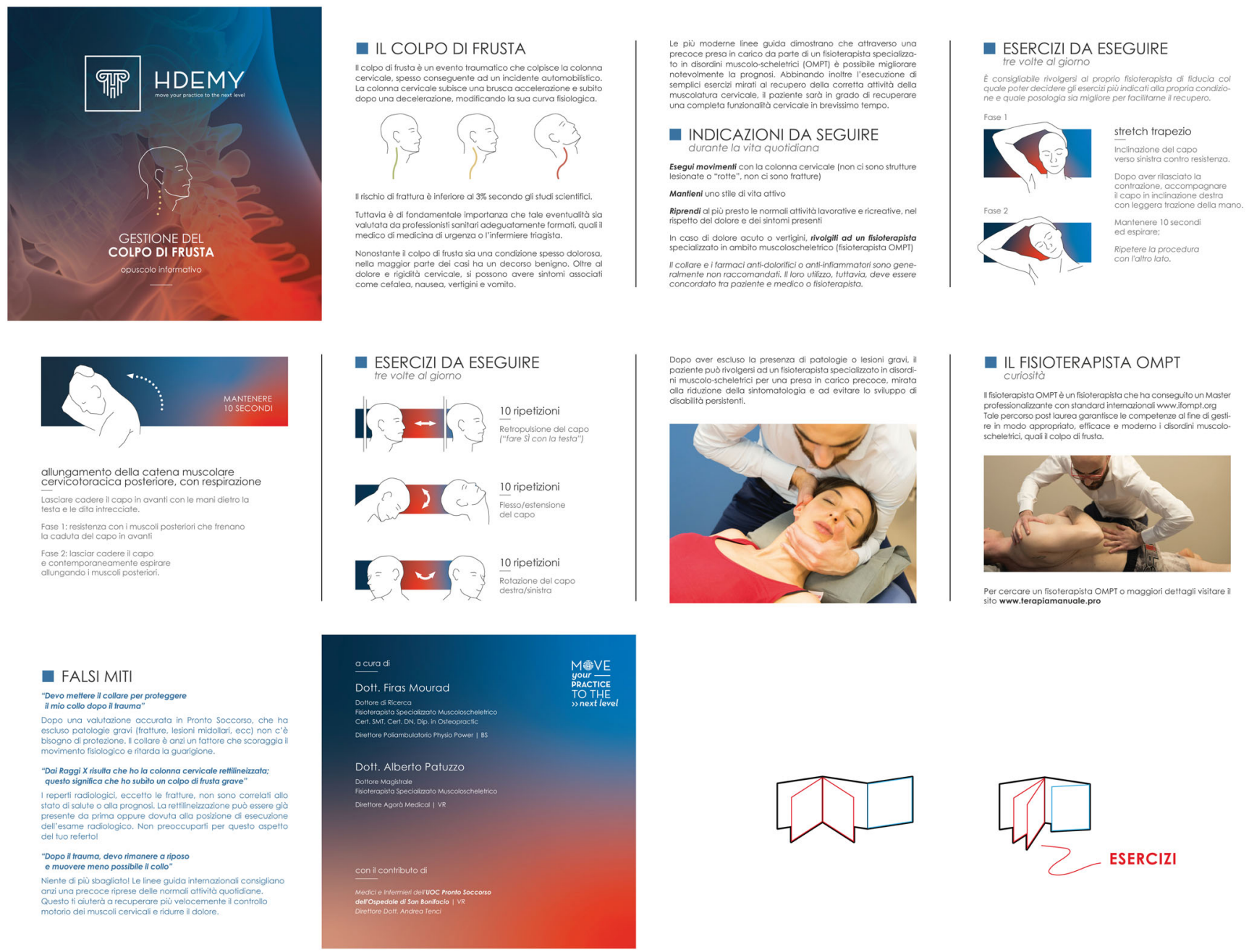

Figure 2. Patient Information Leaflet that ED's physicians handed out to WAD patients during the consultations.

Table 3. ED data and clinical features of WAD patients.

\begin{tabular}{|c|c|c|c|c|c|c|}
\hline & \multicolumn{2}{|c|}{2016} & \multicolumn{2}{|c|}{$2017 / 2018$} & \multirow[b]{2}{*}{ Chi Squared } & \multirow[b]{2}{*}{$p$} \\
\hline & $n$ & $\%$ & $n$ & $\%$ & & \\
\hline ED Total access & 55,134 & - & 54,785 & - & - & - \\
\hline WAD Diagnosis & 3066 & 5.6 & 2185 & 3.9 & 135.5 & $0.001^{*}$ \\
\hline X-rays & 462 & 15.1 & 297 & 13.5 & 1.58 & 0.208 \\
\hline CT Scan & 39 & 1.3 & 41 & 1.9 & 2.63 & 0.105 \\
\hline WAD IV & 22 & 0.7 & 34 & 1.6 & 7.54 & $0.006^{*}$ \\
\hline Orthopaedic referral & 45 & 1.5 & 24 & 1.1 & 1.04 & 0.307 \\
\hline Schanz collar & 271 & 8.8 & 55 & 2.5 & 77.1 & $0.001^{*}$ \\
\hline
\end{tabular}

ED: emergency department; WAD: Whiplash-associated disorders; CT: computed tomography. The percentage refers to WAD patient's population.

*Statistically significant differences between groups $(p<0.05)$.

After the CPD course, the observed small decrease of orthopaedic referrals led to a reduction of waiting times and ED's costs (data not reported) in terms of ED personal workload. Notably, this small change could be explained by the fact the in the Italian health care system, patients seeking care in ED need a physician prescription for their management.

The Schanz collar prescriptions significantly dropped from $8.8 \%$ to $2.5 \%(p=0.001)$. All guidelines agree that collars are contraindicated for WAD I-II-III $[18,26,27]$. Collar prescription is in sharp contrast to the recommendations of staying physically active, acting as usual and promoting mobility [18,27]. An active approach guarantees a reduction of pain intensity and disability compared to cervical immobilization [44,45]. Cervical collar may impede natural recovery by promoting prolonged neck stiffness through inhibiting movement and discouraging patients from taking an active role in their own recovery [46]. Based on our data, it is not possible to know how many cervical collars were prescribed to patients depending on their severity of WAD.

Furthermore, it is important to remember that clinical guidelines recommend addressing negative prognostic factor as first line management strategy by education in addition to physiotherapy $[18,20,21,25-27]$. Generally, WAD is culturally considered pessimistically leading to negative beliefs and behaviors which might cause a recovery delay [47]. Patient information leaflets appear to be highly suited to this context, reinforcing the patient education delivered by ED's physician during the consultation [48]. They play a role in the continuity of care by facilitating hospital to physical therapy referral or home transition, and can be considered as a resource both for patients and doctors, improving patients' knowledge, adherence to treatments and help following the advices provided [49]. Patient Information Leaflets also improve the doctor-patient communication, patient satisfaction and reduce re-attendance to ED for the same pathology after discharge [50].

Our results highlighted several improvements in the management of WADs after the CPD course and this was only possible 
thanks to the collaboration between ED's physician, nurse and OMPT. In an effort to ensure the proper MD referral and to reduce the workload, nurse practitioners and advanced practitioner physiotherapists have gained in the last decade more skills and competences in the first contact, screening and treatment of musculoskeletal injuries in the ED [51-53]. It is common knowledge that physical therapists have been successfully employed as independent care providers in the emergency/acute care setting for more than 40 years in both Australia and the United Kingdom [54]. In the United Kingdom, Ireland, Canada and Australia, "advanced practice," "extended scope," or "primary contact practitioner" physical therapists work as autonomous practitioners, assessing and treating patients independently from physicians and alongside them [55]. An extended scope physiotherapist, nowadays also called Advanced Practitioner Physiotherapist, can potentially manage up to $30 \%$ of the total ED's caseload, reducing significantly the overall ED waiting times [56]. Oakley and Shacklady [57] reported that extended scope physiotherapist have high degree of diagnostic ability in the triage of musculoskeletal disorders, and this is recognized by both patients and doctors. Extended scope physiotherapists obtain equivalent clinical outcomes compared to doctors of all grades, providing a high-quality standard of care at an affordable cost $[53,58]$ and achieving a high level of patient's and ED's staff satisfaction [56,59]. Based on the results achieved and described in other western countries with a similar health system and considering that $13 \%$ of all attendances in Italian EDs are related to musculoskeletal disorders [55], the presence of an extended scope physiotherapist role within the Italian ED multi-disciplinary team would be advantageous. This could lead to better use of resources, reduction of costs and less departmental overload. In Italy, mainly due to legislative limitations, this does not represent the current reality of the local health system organization.

\section{Limitations}

This study was conducted in a single ED center, and in a rural area. In urban and/or bigger centers, perhaps patient and clinician behavior would be different. In addition, a cost-beneficial analysis was not allowed reducing the capability to objectively estimate the potential benefits of the new management strategy in an economical viewpoint.

\section{Conclusion}

Our study informs on how an evidence based structured management for WAD lead to an optimization of the patients' handling and of the human resources position in the ED. We demonstrated that changes can be made by adopting the recommendation of the most recent literature, improving the efficiency of ED without affecting the patients' safety. The most recent guidelines highlighted that providing an early evidence-based care and advice are crucial in the management of WAD patients and the prevention of development of persistent symptoms: the ED can have a significant role for the prognosis of these patients. The introduction of extended scope physiotherapist in ED's multi-disciplinary team might lead to further improvement in ED's service. Further studies to determine whether our findings are replicable in other regions of Italy, urban cities and/or different ED settings are needed.

\section{Acknowledgments}

The authors wish to acknowledge all ED's staff of the hospital Girolamo Fracastoro ED Department for their collaboration.

\section{Disclosure statement}

No potential conflict of interest was reported by the author(s).

\section{ORCID}

Firas Mourad (iD https://orcid.org/0000-0002-8981-2085

Massimiliano Gobbo iD http://orcid.org/0000-0003-1383-6213

Filippo Maselli iD https://orcid.org/0000-0001-9683-9975

\section{References}

[1] Sterling M. Physiotherapy management of whiplash-associated disorders (WAD). J Physiother. 2014;60(1):5-12.

[2] Manchikanti L, Singh V, Datta S, American Society of Interventional Pain Physicians, et al. Comprehensive review of epidemiology, scope, and impact of spinal pain. Pain Physician. 2009;12(4):E35-E70.

[3] Hincapie CA, Cassidy JD, Cote $P$, et al. Whiplash injury is more than neck pain: a population-based study of pain localization after traffic injury. J Occup Environ Med. 2010; 52(4):434-440.

[4] Kenardy J, Heron-Delaney M, Bellamy N, et al. The University of Queensland study of physical and psychological outcomes for claimants with minor and moderate injuries following a road traffic crash (UQ SuPPORT): design and methods. Eur J Psychotraumatol. 2014;5(1):22612.

[5] Kenardy J, Heron-Delaney M, Warren J, et al. Effect of mental health on long-term disability after a road traffic crash: results from the UQ SuPPORT study. Arch Phys Med Rehabil. 2015;96(3):410-417.

[6] Haldeman S, Carroll L, Cassidy JD, Bone and Joint Decade 2000-2010 Task Force on Neck Pain and Its Associated Disorders, et al. The Bone and Joint Decade 2000-2010 Task Force on Neck Pain and Its Associated Disorders: executive summary. Spine (Phila Pa 1976). 2008;33(4 Suppl):S5-S7.

[7] Carroll LJ, Holm LW, Hogg-Johnson S, Bone and Joint Decade 2000-2010 Task Force on Neck Pain and Its Associated Disorders, et al. Course and prognostic factors for neck pain in whiplash-associated disorders (WAD): results of the Bone and Joint Decade 2000-2010 Task Force on Neck Pain and Its Associated Disorders. Spine (Phila Pa 1976). 2008;33(4 Suppl):S83-S92.

[8] Connelly LB, Supangan R. The economic costs of road traffic crashes: Australia, states and territories. Accid Anal Prev. 2006;38(6):1087-1093.

[9] ACI-ISTAT. Rapporto annuale 2015. 2015 [cited 2018 May 02]. Available from: https://casellario.inail.it/cs/cci/comunicazione/news-ed-eventi/istat-non-si-ferma-il-calo-degli-incidenti-e-dei-feriti-i-dati-sono-stati-forniti-dallultimo-rapportoaciistat.html

[10] Commission TQG-MAI. The Motor Accident Insurance Commission Annual Report 2015-16. 2016 [cited 2018 Jun 06]. Available from: https://maic.qld.gov.au/wp-content/ uploads/2016/10/MAIC-Annual-Report-2015-16_WEB.pdf 
[11] Joslin CC, Khan SN, Bannister GC. Long-term disability after neck injury. a Comparative Study. J Bone Joint Surg Br. 2004;86-B(7):1032-1034.

[12] Blincoe L, Miller T, Zaloshnja E, et al. The economic and societal impact of motor vehicle crashes. 2015 [cited 2018 Jun 06]. Available from: https://www.google.com/search?client $=$ safari\&rls=en\&q=Blincoe $+\mathrm{L},+$ Miller $+\mathrm{T},+$ Zaloshnja $+\mathrm{E}$, +et\%C2\%A0al.+The+economic+and+societal+impact+of+ motor+vehicle+crashes.\&ie $=$ UTF-8\&oe $=$ UTF-8

[13] Chappuis G, Soltermann B, CEREDOC. Number and cost of claims linked to minor cervical trauma in Europe: results from the comparative study by CEA, AREDOC and CEREDOC. Eur Spine J. 2008;17(10):1350-1357.

[14] Curatolo $M$, Bogduk N, Ivancic PC, et al. The role of tissue damage in whiplash-associated disorders: discussion paper 1. Spine (Phila Pa 1976). 2011;36(25 Suppl):S309-S15.

[15] Lang J, Dallow N, Lang A, et al. Inclusion of 'minor' trauma cases provides a better estimate of the total burden of injury: Queensland Trauma Registry provides a unique perspective. Injury. 2014;45(8):1236-1241.

[16] Strudwick K, McPhee M, Bell A, et al. Review article: Methodology for the 'rapid review' series on musculoskeletal injuries in the emergency department. Emerg Med Australas. 2018;30(1):13-17.

[17] AM BS. Four Hour Rule Program Progress and Issues Review. Perth: Department of Health WA. 2011 [cited 2018 Jun 06]. Available from: https://www.google.com/search?q= Stokes+B.+Four+Hour+Rule+Program+Progress+ and+Issues+Review.+Perth\%3A+Department+of+Health\% $2 \mathrm{C}+$ Government+of+Western+Australia\%2C+2011\&oq $=$ Stokes+B.+Four+Hour+Rule+Program+Progress+and + Issues+Review.+Perth\%3A+Department+of+Health\% $2 \mathrm{C}+$ Government+of+Western+Australia\%2C+2011\&aqs= chrome.69i57.725j0j4\&sourceid=chrome\&ie=UTF-8

[18] Cote P, Wong JJ, Sutton D, et al. Management of neck pain and associated disorders: a clinical practice guideline from the Ontario Protocol for Traffic Injury Management (OPTIMa) Collaboration. Eur Spine J. 2016;25(7):2000-2022.

[19] Guzman J, Hurwitz EL, Carroll LJ, Bone and Joint Decade 2000-2010 Task Force on Neck Pain and Its Associated Disorders, et al. A new conceptual model of neck pain: linking onset, course, and care: the Bone and Joint Decade 2000-2010 Task Force on Neck Pain and Its Associated Disorders. Spine (Phila Pa 1976). 2008;33(4 Suppl):S14-S23.

[20] Bier JD, Scholten-Peeters WGM, Staal JB, et al. Clinical practice guideline for physical therapy assessment and treatment in patients with nonspecific neck pain. Phys Ther. 2018;98(3):162-171.

[21] Blanpied PR, Gross AR, Elliott JM, et al. Neck Pain: Revision 2017. J Orthop Sports Phys Ther. 2017;47(7):A1-A83.

[22] (SIRA) SIRA. State Insurance Regulatory Authority: Guidelines for the management of acute whiplash-associated disorders - for health professionals 3rd Edition. 2014 [cited 2018 May 15]. Available from: https://www.sira.nsw. gov.au/resources-library/motor-accident-resources/publications/for-professionals/whiplash-resources/SIRA08104Whiplash-Guidelines-1117-396479.pdf

[23] Coffey F, Hewitt S, Stiell I, et al. Validation of the Canadian c-spine rule in the UK emergency department setting. Emerg Med J. 2011;28(10):873-876.

[24] Hoffman JR, Wolfson AB, Todd K, et al. Selective cervical spine radiography in blunt trauma: methodology of the
National Emergency X-Radiography Utilization Study (NEXUS). Ann Emerg Med. 1998;32(4):461-469.

[25] Strudwick K, McPhee M, Bell A, et al. Review article: best practice management of neck pain in the emergency department (part 6 of the musculoskeletal injuries rapid review series). Emerg Med Australas. 2018;30(6):754-772.

[26] Bussieres AE, Stewart G, Al-Zoubi F, et al. The treatment of neck pain-associated disorders and whiplash-associated disorders: a clinical practice guideline. J Manipulative Physiol Ther. 2016;39(8):523-564.e27.

[27] Wong JJ, Cote P, Shearer HM, et al. Clinical practice guidelines for the management of conditions related to traffic collisions: a systematic review by the OPTIMa Collaboration. Disabil Rehabil. 2015;37(6):471-489.

[28] Moser N, Lemeunier N, Southerst D, et al. Validity and reliability of clinical prediction rules used to screen for cervical spine injury in alert low-risk patients with blunt trauma to the neck: part 2. A systematic review from the Cervical Assessment and Diagnosis Research Evaluation (CADRE) Collaboration. Eur Spine J. 2018;27(6):1219-1233.

[29] Kerr D, Bradshaw L, Kelly AM. Implementation of the Canadian C-spine rule reduces cervical spine $\mathrm{X}$-ray rate for alert patients with potential neck injury. J Emerg Med. 2005;28(2):127-131.

[30] Stiell IG, Clement CM, Lowe M, et al. A multicenter program to implement the canadian c-spine rule by emergency department triage nurses. Ann Emerg Med. 2018; 72(4):333-341.

[31] Griffith B, Kelly $M$, Vallee $P$, et al. Screening cervical spine $\mathrm{CT}$ in the emergency department, Phase 2: a prospective assessment of use. AJNR Am J Neuroradiol. 2013;34(4): 899-903.

[32] Holmes JF, Akkinepalli R. Computed tomography versus plain radiography to screen for cervical spine injury: a meta-analysis. J Trauma. 2005;58(5):902-905.

[33] Ngatchou W, Beirnaert J, Lemogoum D, et al. Application of the Canadian C-Spine rule and nexus low criteria and results of cervical spine radiography in emergency condition. Pan Afr Med J. 2018;30:157.

[34] Gale SC, Gracias VH, Reilly PM, et al. The inefficiency of plain radiography to evaluate the cervical spine after blunt trauma. J Trauma. 2005;59(5):1121-1125.

[35] Hanson JA, Blackmore CC, Mann FA, et al. Cervical spine injury: a clinical decision rule to identify high-risk patients for helical CT screening. AJR Am J Roentgenol. 2000;174(3): 713-717.

[36] Bailitz J, Starr F, Beecroft M, et al. CT should replace threeview radiographs as the initial screening test in patients at high, moderate, and low risk for blunt cervical spine injury: a prospective comparison. J Trauma. 2009;66(6):1605-1609.

[37] Hunter BR, Keim SM, Seupaul RA, et al. Are plain radiographs sufficient to exclude cervical spine injuries in lowrisk adults? J Emerg Med. 2014;46(2):257-263.

[38] Rybicki F, Nawfel RD, Judy PF, et al. Skin and thyroid dosimetry in cervical spine screening: two methods for evaluation and a comparison between a helical CT and radiographic trauma series. AJR Am J Roentgenol. 2002; 179(4):933-937.

[39] Smith AB, Dillon WP, Lau BC, et al. Radiation dose reduction strategy for $C T$ protocols: successful implementation in neuroradiology section. Radiology. 2008;247(2):499-506. 
[40] Kanwar R, Delasobera BE, Hudson K, et al. Emergency department evaluation and treatment of cervical spine injuries. Emerg Med Clin North Am. 2015;33(2):241-282.

[41] Blackmore CC, Ramsey SD, Mann FA, et al. Cervical spine screening with $C T$ in trauma patients: a cost-effectiveness analysis. Radiology. 1999;212(1):117-125.

[42] Michaleff ZA, Maher CG, Verhagen AP, et al. Accuracy of the Canadian C-spine rule and NEXUS to screen for clinically important cervical spine injury in patients following blunt trauma: a systematic review. CMAJ. 2012;184(16): E867-E876.

[43] Stiell IG, Bennett C. Implementation of clinical decision rules in the emergency department. Acad Emerg Med. 2007;14(11):955-959.

[44] Borchgrevink GE, Kaasa A, McDonagh D, et al. Acute treatment of whiplash neck sprain injuries. A randomized trial of treatment during the first 14 days after a car accident. Spine (Phila Pa 1976). 1998;23(1):25-31.

[45] Schnabel M, Ferrari R, Vassiliou T, et al. Randomised, controlled outcome study of active mobilisation compared with collar therapy for whiplash injury. Emerg Med J. 2004; 21(3):306-310.

[46] Teasell RW, McClure JA, Walton D, et al. A research synthesis of therapeutic interventions for whiplash-associated disorder (WAD): part 2 - interventions for acute WAD. Pain Res Manag. 2010;15(5):295-304.

[47] Bostick GP, Ferrari R, Carroll LJ, et al. A population-based survey of beliefs about neck pain from whiplash injury, work-related neck pain, and work-related upper extremity pain. Eur J Pain. 2009;13(3):300-304.

[48] Grime J, Blenkinsopp A, Raynor DK, et al. The role and value of written information for patients about individual medicines: a systematic review. Health Expect. 2007;10(3): 286-298.

[49] Sustersic M, Gauchet A, Foote A, et al. How best to use and evaluate Patient Information Leaflets given during a consultation: a systematic review of literature reviews. Health Expect. 2017;20(4):531-542.

[50] Sustersic $M$, Tissot $M$, Tyrant J, et al. Impact of patient information leaflets on doctor-patient communication in the context of acute conditions: a prospective, controlled, before-after study in two French emergency departments. BMJ Open. 2019;9(2):e024184.

[51] Ball ST, Walton K, Hawes S. Do emergency department physiotherapy practitioner's, emergency nurse practitioners and doctors investigate, treat and refer patients with closed musculoskeletal injuries differently? Emerg Med J. 2007;24(3):185-188.

[52] Kilner E, Sheppard L. The 'lone ranger': a descriptive study of physiotherapy practice in Australian emergency departments. Physiotherapy. 2010;96(3):248-256.

[53] McClellan C, Cramp F, Powell J, et al. Extended scope physiotherapists in the emergency department: a literature review. Physical Therapy Reviews. 2010;15(2):106-111.

[54] Courtney DM. Assessment and management of whiplash from the emergency and acute care setting: care, questions, and future global research needs. J Orthop Sports Phys Ther. 2016;46(10):822-825.

[55] de Gruchy A, Granger C, Gorelik A. Physical therapists as primary practitioners in the emergency department: sixmonth prospective practice analysis. Phys Ther. 2015;95(9): 1207-1216.

[56] McClellan CM, Greenwood R, Benger JR. Effect of an extended scope physiotherapy service on patient satisfaction and the outcome of soft tissue injuries in an adult emergency department. Emerg Med J. 2006;23(5):384-387.

[57] Oakley C, Shacklady C. The clinical effectiveness of the extended-scope physiotherapist role in musculoskeletal triage: a systematic review. Musculoskeletal Care. 2015;13(4): 204-221.

[58] McClellan CM, Cramp F, Powell J, et al. A randomised trial comparing the cost effectiveness of different emergency department healthcare professionals in soft tissue injury management. BMJ Open. 2013;3(1):e001116.

[59] Taylor NF, Norman E, Roddy L, et al. Primary contact physiotherapy in emergency departments can reduce length of stay for patients with peripheral musculoskeletal injuries compared with secondary contact physiotherapy: a prospective non-randomised controlled trial. Physiotherapy. 2011;97(2):107-114. 